\title{
DIREITO TRIBUTÁRIO AMBIENTAL: BENEFÍCIOS FISCAIS ÀS EMPRESAS PARA PROTEÇÃO DO DIREITO FUNDAMENTAL AO MEIO AMBIENTE*
}

\section{ENVIRONMENTAL TRIBUTARY LAW: FISCAL BENEFITS TO COMPANIES FOR PROTECTION OF THE FUNDAMENTAL RIGHT TO ENVIRONMENT}

\author{
Samia Moda Cirino" \\ Marlene Kempfer Bassoli:
}

\begin{abstract}
Resumo: Demonstra que para a concretização do direito fundamental ao meio ambiente é necessário que o Estado intervenha na Ordem Econômica a fim de implementar políticas ambientais que redirecionem a racionalidade da iniciativa privada e consumidores a práticas ambientalmente desejáveis. Para tal finalidade, enfatiza-se a eficiência dos instrumentos econômicos por intermédio dos institutos do Direito Tributário Ambiental. Por meio da instituição de tributos ou pela concessão de benefícios fiscais é possível a indução a práticas ambientalmente adequadas. Constata que a política tributária ambiental no Brasil deve ocorrer por intermédio de benefícios fiscais, instrumentos mais apropriados para desestimular a poluição e fomentar práticas ambientais responsáveis.
\end{abstract}

Palavras-chave: Benefícios fiscais. Tributos Instrumentos econômicos. Responsabilidade social.

Abstract: This work demonstrates that, for the materialization of the fundamental right to environment, it is necessary that the State intervenes in the Economic Order so as to implement environmental policies that redirect both private initiative and consumers to desirable practices. For such an aim, the efficiency of economic instruments is emphasized by means of the Environmental Tributary Law. Through tributes or concession of fiscal benefits it is possible to induce appropriate practices. This research

Artigo extraído da Dissertação de Mestrado, apresentada ao Programa de Pós-Graduação Stricto Sensu da Universidade Estadual de Londrina, de autoria do primeiro, sob a orientação do segundo.

Mestre em Direito Negocial, na área de concentração em Direito Empresarial.

Doutora em Direito do Estado - Direito Tributário pela PUC-SP. Professora dos Programas de Mestrado em Direito da Universidade Estadual de Londrina - UEL e da Universidade de Marília - UNIMAR. 
confirms that the environmental tributary policies in Brazil should take the form of fiscal benefits, instruments considered more appropriate to discourage pollution and foment responsible environmental practices.

Keywords: Fiscal incentive. Tributes Economic instruments. Social responsibility.

\section{INTRODUÇÃO}

A relação homem-natureza é marcada por profundos problemas oriundos, em grande parte, de uma racionalidade instrumental de cunho utilitarista que encara o homem como um ser situado fora da natureza. Em busca do desenvolvimento econômico e social, a natureza é explorada esquecendo que o ser humano dela depende para a sua sobrevivência e qualidade de vida. Ainda que nessa relação o homem altere o meio ambiente, este, por sua vez, também provoca alterações no homem. O fundamento relacional que une o homem e a natureza é a influência recíproca que um exerce sobre o outro.

A atividade econômica também é dependente do meio ambiente, seja como fonte de recursos naturais ou como depósito para os resíduos resultantes da produção e do consumo, o que evidencia a constatação de que o processo econômico tende a esbarrar irreversivelmente em restrições ambientais. A perspectiva, pois, concentra-se na busca do direcionamento do modelo econômico a soluções baseadas em incentivos que encorajem os comportamentos ambientalmente desejáveis.

As relações humanas no nível do domínio econômico estão sendo pressionadas pela opinião pública a adotarem uma conduta ética na sua atuação co-responsável para com a sociedade e o meio ambiente. A busca de excelência pelas empresas passa a ter como objetivos a qualidade nas relações e a sustentabilidade econômica, social e ambiental. Essas mudanças fazem crescer o número de empresas que se voltam à chamada responsabilidade social. Tratase de uma forma diversa de conduzir os negócios, levando em conta os interesses de um conjunto maior de partes interessadas, tornando-se co-responsáveis pelo desenvolvimento econômico, social e cultural da sociedade.

Mas essa ainda não parece ser a mentalidade predominante na gestão empresarial. Devido a uma inadequada avaliação econômica muitas empresas não se preocupam com as externalidades negativas que causam ao meio ambiente. É nesse sentido que emerge o papel do Estado de intervir sobre a Ordem Econômica a fim de garantir o direito fundamental ao meio ambiente equilibrado, expresso no Art. 225 da Constituição Federal de 1988. 
Direito tributário ambiental: benefícios fiscais às empresas para proteção...

A Carta Magna brasileira no Art. 174 permite que o Estado intervenha na seara econômica a fim de concretizar os princípios orientadores da Ordem Jurídico-Econômica. De tal modo, analisando o Art. 170, VI, verifica-se que há autorização constitucional para a intervenção do Estado sobre a economia para implementar políticas públicas ambientais com finalidade de proteger e induzir condutas dos agentes econômicos em relação ao meio ambiente.

Nessa atividade interventiva, o Estado tem à disposição instrumentos de duas ordens: instrumentos normativos e instrumentos econômicos. Verificada a necessária conjugação desses mecanismos para uma política ambiental adequada, confere-se, nesta pesquisa, maior ênfase aos institutos do Direito Tributário Ambiental. Isso em razão da tributação ter o potencial de induzir o contribuinte a práticas sociais e econômicas adequadas à preservação e recuperação da qualidade do meio ambiente.

Entretanto, o cerne da questão no Direito Tributário Ambiental é se a proteção do meio ambiente deve ocorrer pela instituição de novos tributos ou por meio da concessão de benefícios fiscais. Embora a tributação ambiental seja um importante instrumento para concretizar o princípio do poluidorpagador, levando as empresas a internalizarem os custos sociais, diante da realidade econômico-social brasileira, não parece ser o melhor caminho a majoração da carga tributária. Políticas públicas afirmativas consubstanciadas em benefícios fiscais podem trazer resultados mais eficientes para a preservação do meio ambiente, pois são calcados em atrativos econômico-financeiros que, sem asfixiar a atividade econômica, inserem na iniciativa privada e consumidores a mentalidade ambiental.

\section{RESPONSABILIDADE SOCIAL DA EMPRESA}

Os problemas ambientais apresentam-se como uma das principais ameaças da atual sociedade. Esse fato tem modificado as bases do mundo dos negócios. Todas as fases da atividade econômica passaram a ser rodeadas por outras expectativas, isto é, por outros agentes e considerações. Essa é a nova configuração que se impõe às empresas: ética e responsabilidade para com a sociedade e o meio ambiente.

Um novo modelo de empresa está sendo exigido tanto por grupos sociais de pressão, quanto pelo próprio consumidor. Diante dessas mudanças, cresce o número de empresas que se voltam à chamada responsabilidade social. Frisase, de início, que esse termo abrange tanto as ações especificamente sociais (como educação, lazer, cultura, qualificação profissional), como aquelas voltadas à proteção do meio ambiente. 
Felipe Corrêa e João Ricardo Medeiros (2003) definem a responsabilidade social da empresa como uma forma de conduzir seus negócios, de modo a tornarse parceira e co-responsável pelo desenvolvimento econômico, social e cultural da sociedade. Essa empresa-cidadã busca os interesses das diferentes partes interessadas ou stakeholders (acionistas, funcionários, fornecedores, consumidores, comunidade, governo e meio ambiente) incorporando-os no planejamento de suas atividades, atendendo, portanto, às demandas de todos os envolvidos e não apenas dos acionistas ou shareholders.

Quando se fala em responsabilidade social é preciso cuidado para não confundi-la com a função social ou obrigação social imposta pela legislação às empresas. Uma empresa somente deve ser considerada socialmente responsável quando vai além da obrigação de respeitar as leis, pagar tributos e observar as condições adequadas de segurança e saúde para os trabalhadores. A obrigação social corresponde, portanto, àquilo que a empresa faz pelo social em vista de uma previsão legal. Já a responsabilidade social pressupõe que a empresa considere as metas econômicas e sociais nas suas decisões e vá além dos limites da legislação.

As ações sociais implementadas pelas empresas ainda são muito questionadas quanto a sua legitimidade. Nos moldes em que são realizadas, tratam-se apenas de uma questão de marketing beneficente, ou seja, uma estratégia de mercado eficiente a fim de construir uma imagem pública positiva. Embora o marketing beneficente seja um importante instrumento na inserção e promoção de uma empresa ou produto em um mercado, a responsabilidade social não deve ser reduzida a uma mera estratégia mercadológica.

A responsabilidade social não expressa uma ação emergencial e pontual das empresas de ajudar o social. Pelo contrário, reflete uma perspectiva consciente das empresas de incorporarem em sua mentalidade e na de seus colaboradores a busca do bem-estar da população, por perceber que o próprio desenvolvimento da organização depende da sociedade à qual pertencem. Adquirida essa mentalidade, tal responsabilidade deve ser traduzida em estratégias e atitudes cotidianas que coloquem em prática os citados valores e objetivos, instituindo órgãos de avaliação permanente de sua gestão social e, principalmente, implementando consultas à comunidade, possibilitando, assim, que a população também participe desse processo.

Contudo, a ética, antes de ser um valor inerente ao negócio, ainda é entendida como mais um recurso a ser utilizado para atingir os objetivos empresariais. Além disso, a participação dos cidadãos beneficiários na elaboração de projetos sociais ainda é muito tímida, quando não é inexistente. Essa racionalidade estratégica faz que as empresas estabeleçam com a sociedade 
Direito tributário ambiental: benefícios fiscais às empresas para proteção...

uma relação hierarquizada, com a determinação quase unilateral de procedimentos e metas, ao invés de uma interação participativa, a qual pressupõe um diálogo aberto para a busca de um consenso entre as partes (FABIÃO, 2003).

Não se busca com esse posicionamento transformar as empresas em organizações não-governamentais. Para se compatibilizar lucro com responsabilidade social, é importante enfatizar que a definição de responsabilidade social não se coloca como uma questão de deixar de realizar lucros, não é uma autotributação ou uma oposição ao comportamento maximizador de riquezas (GUALTIERI et al., 2003). Não serve para uma nova ordem da economia mundial a mera ética da economia idealista, para a qual é suficiente uma motivação puramente moral, mas que não leva adequadamente em conta a ordem econômica dada e o que é concretamente viável num sistema econômico altamente complexo. Não adianta levantar exigências morais que carecem de toda racionalidade econômica e que, portanto, não consideram as leis próprias da economia.

Uma atividade econômica responsável consiste em unir estratégias econômicas com o julgamento ético. Esse novo paradigma de ethos econômico passa a ser concreto quando, não obstante a legitimidade do lucro, analisa o agir econômico para ver se não ofende bens e valores mais elevados, se é social e ecologicamente aceitável (KÜNG, 1999). Da arte da atividade econômica bem-sucedida faz parte avaliar não apenas os efeitos intencionados (como o aumento da produção), mas também os efeitos não intencionados, que muitas vezes são extremamente graves (como a poluição ambiental). Hans Küng (1999) destaca:

A ética empresarial agora deve ser concebida como a base normativa interna de toda bem-sucedida estratégia empresarial legitima, responsável e com sentido prático para a vida - de certa forma como o piso de valores sobre o qual assenta uma política empresarial e estratégica de negócios (p. 409).

\section{O DIREITO FUNDAMENTAL AO MEIO AMBIENTE NA CONSTITUIÇÃO FEDERAL}

O direito ao meio ambiente consubstancia-se em um direito fundamental de terceira dimensão. Bonavides (2003) lembra que esses direitos nascem da consciência de um mundo divido entre nações desenvolvidas e subdesenvolvidas, ou em fase de precário desenvolvimento, o que levou a reflexão sobre temas referentes ao desenvolvimento, paz, meio ambiente, comunicação e patrimônio comum da humanidade. Fundados no valor 
fraternidade e dotados de altíssimo teor de humanismo e universalidade, cristalizam-se no fim do século XX enquanto direitos que não se destinam especificamente à proteção dos interesses de um indivíduo, de um grupo ou de um determinado Estado. Têm por destinatário o próprio gênero humano.

O reconhecimento e a proteção dos direitos do homem estão nas bases das Constituições democráticas modernas. Nesse sentido, também a Constituição Federal de 1988, no Capítulo VI, Art. 225, trouxe inúmeras inovações ao ordenamento jurídico brasileiro referente ao direito fundamental ao meio ambiente. Primeiramente erigiu o meio ambiente à condição de bem do uso comum do povo, conferindo a todos o direito de tê-lo ecologicamente equilibrado. Em contrapartida, requereu uma maior participação da sociedade para a tutela ambiental, na medida que determinou sua defesa e preservação para as presentes e futuras gerações tanto ao Poder Público como à coletividade. Buscou, igualmente, assegurar um desenvolvimento econômico e social sustentável, coibindo o uso indiscriminado e predatório dos recursos naturais. O Art. 225 não estabelece apenas um direito subjetivo, mas também uma imposição objetiva, um autêntico mandamento constitucional a ser cumprido pelo Poder Público e, mormente, pelos responsáveis por atividades degradantes da qualidade e equilíbrio ambiental.

Entre as mudanças na questão ambiental merece destaque o fato do legislador constituinte ter buscado inserir o conteúdo humano e social no conceito de meio ambiente. Ora, meio ambiente não se reduz aos elementos naturais (ar, água, terra etc.). Consoante ensina Paulo de Bessa Antunes (2005), deve ser compreendido como "o conjunto das condições de existência humana, que integra e influencia o relacionamento entre homens, sua saúde e seu desenvolvimento" (p. 75). Por isso que o conceito estabelecido na Lei da Política Nacional do Meio Ambiente merece críticas, já que a definição legal considera o meio ambiente do ponto de vista puramente biológico, excluindo o aspecto social.

Em relação à natureza jurídica do bem ambiental, Celso Fiorillo (2004) explica que a Carta Magna consagrou no Art. 225 a existência de um bem que não é público nem particular, mas sim um bem de uso comum do povo. $O$ direito ao ambiente é de cada pessoa, mas não somente dela, sendo, portanto, transindividual. Nesse contexto, Paulo Affonso Machado (2005) entende que o Poder Público passou a figurar não como proprietário de bens ambientais, mas como um gestor que administra bens que não são dele, e por isso deve explicar convincentemente sua gestão. Esse posicionamento impõe ao Poder Público o dever de prestar contas sobre a administração e a utilização dos 
Direito tributário ambiental: benefícios fiscais às empresas para proteção...

bens de uso comum do povo, bem como implica na necessidade de uma maior participação da sociedade na gestão do meio ambiente, já que o povo é o titular do bem ambiental.

Complementa-se que o objeto do direito estabelecido no caput do Art. 225 da Constituição Federal não é o meio ambiente em si, e sim o meio ambiente qualificado, equilibrado ecologicamente. Para Edis Milaré (2004) essa qualidade é que se converteu em um bem jurídico. A isso é que a Carta Magna definiu como "bem de uso comum do povo essencial à sadia qualidade de vida”. Trata-se de bem de interesse público, dotado de um regime jurídico especial, enquanto essencial à sadia qualidade de vida e vinculado a um fim de interesse coletivo.

\section{INTERVENÇÃO DO ESTADO NA ORDEM ECONOMICA PARA PROTEÇÃO DO MEIO AMBIENTE}

Diante do acirramento dos problemas sociais e ambientais a empresa ganhou novo papel, no sentido de buscar não apenas o crescimento econômico, mas também de promover ações socialmente responsáveis. Mas, devido a uma avaliação econômica errada, algumas empresas não se preocupam com as externalidades negativas que causam ao meio ambiente. Ou seja, empresas que não entendem a importância da responsabilidade social empresarial discordam a respeito da proteção do meio ambiente: para a maioria, reciclar é mais caro do que comprar novas matérias-primas; gerenciamento dos resíduos consome tempo e esforços que poderiam ser alocados aos processos produtivos.

Enquanto essa responsabilidade não é atingida, é necessário que o Estado intervenha na ordem econômica voltando os agentes econômicos a práticas ambientais mais adequadas. A redação dada ao Art. 170 da Constituição Federal demonstra a opção do legislador constituinte por uma ordem econômica liberal e modo de produção capitalista. Entretanto, a Constituição dá contornos próprios ao capitalismo, ajustando-o à exigências de razões econômicas e sociais. Para tanto, previu no Art. 174 a possibilidade de intervenção do Estado no domínio econômico, visando garantir o rol de princípios estabelecidos no referido Art. 170, dentre os quais destaca-se, no inciso VI, a proteção do meio ambiente.

O Art. 174 da Carta Magna fixa os limites da intervenção estatal. Prescreve que a ação interventiva do Estado no domínio econômico pode ocorrer como agente normativo e regulador da iniciativa privada. Para essas finalidades deve observar os princípios da ordem econômica informados no Art. 170 da Constituição. 
Como agente normativo, o Estado impõe normas e mecanismos jurídicos de cunho preventivo e repressivo, visando evitar ou sanar possíveis condutas abusivas. A normatização apresenta-se como a produção de normas com o objetivo de instrumentalizar a realização das políticas econômicas adotadas pela Constituição.

Já na função de regulador da atividade econômica, o Estado disciplina os comportamentos dos particulares, influenciando suas esferas de liberdade a fim de garantir a segurança e higidez do mercado. $O$ termo regulação pode ser empregado em uma acepção ampla. Engloba toda a forma de organização da atividade econômica pelo Estado. Pode atuar, portanto, como agente fiscalizador, no exercício do poder de polícia, averiguando e reprimindo condutas incondizentes com os fundamentos e princípios da ordem econômica (Art. 170 da CF). Atua, ainda, como promotor da atividade econômica, sob a forma de ações fomentadoras, consubstanciadas em benefícios e estímulos à propriedade privada.

Como agente regulador, visando à proteção do meio ambiente, Jorge Hernández Jiménez (1998, p. 55-56) destaca que o Estado tem à disposição instrumentos de duas ordens distintas: os instrumentos normativos e os instrumentos econômicos. Os instrumentos normativos consistem em: comandos de controle de emissão ou limitação ao uso de recursos, fiscalização, aplicação de sanção sobre o infrator e exigência à reparação do dano ambiental ocorrido (MODÉ, 2004). A aplicação dos instrumentos normativos na gestão ambiental procura disciplinar o comportamento dos agentes econômicos, impondo ou proibindo determinadas condutas e estabelecendo limites máximos para o uso dos recursos naturais ou para a geração de efluentes.

A eficiência desses mecanismos depende, fundamentalmente, das sanções previstas na legislação, aplicáveis aos renitentes em atender aos limites regulatórios. A idéia é de que os agentes econômicos que utilizam recursos ambientais tendem a acatar as diretrizes legais quando os custos gerados pelas penalidades forem significativamente altos. As multas de valor elevado ou mesmo a imposição de embargos e suspensões das atividades dos infratores acarretam para o poluidor um ônus econômico maior do que o benefício obtido com a eventual transgressão da norma, induzindo-o a observar a política de controle (CARNEIRO, 2003).

Porém, o processo de formulação dessas políticas regulatórias nos parlamentos ou nas agências governamentais é sujeito à atuação de determinados grupos de interesse, que acabam influenciando em seu favor a definição dos parâmetros de emissão e dos patamares punitivos. Além disso, 
os custos administrativos dos mecanismos normativos são, em geral, muito elevados: mobilização de fiscais, estruturas e equipamentos de apoio, estudos e análises contínuas, visando à obtenção de dados que subsidiem o estabelecimento de normas técnicas e de padrões ambientais, entre outros. A esse aspecto agrega-se o fato dessa forma de regulação direta mostrar-se quase sempre incapaz de incentivar os agentes econômicos a melhorar sua eficiência ambiental, uma vez que, quando atingido o padrão legalmente fixado não estarão obrigados a implementar novos aprimoramentos tecnológicos.

Os instrumentos econômicos visam complementar os mecanismos normativos e corrigir, indiretamente, as disfunções ambientais. A sua principal característica consiste na pressão indireta que exercem sobre as atividades poluidoras, influenciando no custo dos bens e serviços, induzindo a condutas menos deletérias. Dentre esses instrumentos destaca-se a tributação ambiental, como eficiente mecanismo econômico capaz de induzir as atividades privadas a adotarem técnicas e produtos menos poluentes. O Direito Tributário Ambiental, por meio da extrafiscalidade, possui nos tributos e nos benefícios fiscais importantes instrumentos na luta contra a degradação do meio ambiente.

Embora os instrumentos econômicos carreguem o ideal de mudança social, uma política ambiental adequada deve adotar conjuntamente os mecanismos econômicos e os normativos. Ricardo Carneiro (2003) alerta que se fosse adotada uma política ambiental baseada exclusivamente em instrumentos de índole econômica os poluidores teriam flexibilidade para reagir aos estímulos econômicos de modo e no tempo que melhor lhes conviesse, minimizando seus custos privados e aumentando os custos sociais. "Somente assim a indústria irá ajustar suas emissões aos níveis legalmente estabelecidos e ainda poderá ter estímulos econômicos para implementar reduções adicionais da poluição” (CARNEIRO, 2003, p. 77).

\section{DIREITO TRIBUTÁRIO AMBIENTAL}

A partir do momento que a Constituição estabeleceu no Art. 170, VI, a proteção do meio ambiente como princípio orientador da ordem econômica, presente está a autorização constitucional para que o Estado intervenha no domínio econômico, visando garantir a observância a esse preceito fundamental. Para essa finalidade, os institutos tributários destacam-se pela sua capacidade de compensação das externalidades decorrentes das atividades econômicas e, principalmente, pelo seu potencial de indução a práticas sociais e econômicas adequadas à preservação da qualidade ambiental, cristalizando bases para um desenvolvimento sustentável. 
A atuação do Estado para implementação de políticas públicas tem nos mecanismos do Direito Tributário o seu mais relevante instrumento de ação e em relação aos quais dificilmente poderá dispor de outro meio tão eficiente. Nesse sentido, os tributos podem ser utilizados como um importante instrumento de política ambiental, ao lado de outras medidas de orientação de condutas, onerando ou beneficiando as atitudes dos particulares em relação ao meio ambiente.

Heleno Taveira Tôrres (2005) apresenta o Direito Tributário Ambiental como ramo do Direito Tributário que tem por objeto "o estudo das normas jurídicas tributárias elaboradas em concurso com o exercício de competências ambientais, para determinar o uso de tributo na função instrumental de garantia, promoção ou preservação de bens ambientais” (p. 101). Visa, portanto, a regulação, disciplina, organização das atividades utilizadoras de recursos ambientais, compelindo-as a uma atuação mais racional por meio do adequado controle e gestão dos insumos naturais. Verifica-se uma interseção entre o Direito Tributário e o Direito Ambiental, ambos se atraindo para imprimir um papel inovador ao Direito Tributário, no sentido de alteração de condutas em relação ao meio ambiente.

\subsection{Tributação Extrafiscal}

Para a concepção liberal clássica, que parte da idéia de uma sociedade autônoma, auto-regulada e separada do Estado e, correlativamente, de um Estado neutro e mínimo, o tributo apresenta uma função exclusivamente fiscal. A finalidade do tributo deveria ser apenas a de obtenção de receitas limitadas às imprescindíveis para a realização das tarefas do Estado.

O entendimento liberal de tributo passou a ser insuficiente para compreensão das profundas alterações ocorridas com o advento do Estado de Bem-Estar. Para Cesar Novoa (2000) os tributos, além de ser meios para arrecadar ingressos públicos, também passaram a servir como instrumentos da política econômica geral, atendendo às exigências de estabilidade, desenvolvimento social e melhor distribuição da renda nacional. Pode-se dizer que essas motivações de interesse geral se identificam com o interesse público existente nas normas tributárias, ao que se denomina fim extrafiscal do tributo.

Ficher entende a extrafiscalidade como um importante instrumento à disposição do Estado na sua atividade de conformação da ordem econômica e social. Acredita que os objetivos extrafiscais dos tributos não são apenas admissíveis, mas também exigíveis. A atividade tributária deve concorrer diretamente para a prossecução dos fins constitucionais, nos quais se inclui a 
modificação da base econômica e social para a realização da igualdade de fato (FICHER, 1993, apud NABAIS, 1998, p. 241).

Em contrapartida, José Nabais adverte que a utilização extrafiscal dos tributos deve ocorrer de forma cautelosa. Deve constituir uma clara exceção: "A porta do intervencionismo não está aberta aos impostos sem limitações constitucionais”. O tributo é um instrumento que se presume orientado por um objetivo principalmente fiscal (NABAIS, 1998, p. 247). Portanto, não pode ser transformado em instrumento normal de intervenção econômico-social; deve ser uma exceção cabível apenas nos casos que a própria Constituição permite.

O Direito Tributário Ambiental emprega os instrumentos tributários com finalidade dúplice: a fiscal ou arrecadatória, voltada à obtenção de receitas que serão aplicadas em ações que promovam a defesa do meio ambiente; e a extrafiscal ou regulatória, tendente a induzir comportamentos que sejam ambientalmente responsáveis, seja por meio de uma maior tributação, concretizada em tributos ecológicos ou até em agravamentos ecológicos de impostos, seja por intermédio de benefícios fiscais.

A extrafiscalidade pode ser implementada mediante a instituição e o agravamento de tributos, concessão de isenções e outros benefícios fiscais. Tem como objetivo principal a interferência no domínio econômico, buscando um efeito diverso da simples arrecadação de recursos financeiros. Esse efeito diverso consiste na indução da sociedade e iniciativa privada a práticas ambientalmente desejáveis, a fim de que a preservação ambiental esteja implementada nos sistemas de produção e consumo.

Caracteriza-se pela utilização do tributo como meio de fomento ou de desestímulo a atividades reputadas, convenientes ou inconvenientes à comunidade. Com efeito, por intermédio da agravação de impostos podem ser modificadas as atitudes dos particulares reputadas contrárias ao interesse público, bem como há possibilidade do abrandamento da tributação como forma de incentivar condutas convenientes à sociedade.

\subsection{Tributação Ambiental}

O Direito Tributário Ambiental utiliza os mecanismos tributários para implementar políticas públicas ambientais, seja instituindo novos tributos ou majorando os já existentes, seja por intermédio dos benefícios fiscais. A adoção de tributos ambientais busca concretizar o princípio do poluidorpagador, mediante a internalização dos custos ambientais da produção (externalidades negativas). O tributo ambiental consiste no pagamento pelos 
agentes econômicos de um valor proporcional aos custos externos causados pela degradação ao meio ambiente. Com isso, os custos nos quais a sociedade incorre ao suportar os danos externos negativos causados pelos poluidores são a ela ressarcidos por meio da obrigação tributária.

Pietro Selicato (2005) apresenta a classificação de tributos ambientais em sentido estrito, os quais assumem os comportamentos poluentes como verdadeiros fatos jurídicos tributários; e os tributos com função ambiental, nos quais a tutela do meio ambiente ocorre principalmente pela finalidade extrafiscal, assumindo a função político-social de desestimular os comportamentos nocivos ao ambiente ou de encorajar os ambientalmente corretos. Diante dessa classificação, adota-se como tributos ambientais aqueles instituídos especificamente para tutela ambiental, nos quais o comportamento nocivo ao meio ambiente é internalizado como suporte dos critérios da regra-matriz de incidência fiscal. Já os tributos com finalidade ambiental não são instituídos com essa finalidade específica, mas por meio da extrafiscalidade, majorando ou diminuindo alíquotas, por exemplo, é possível imprimir-lhes o escopo de proteção do meio ambiente

Uma importante vantagem da tributação ambiental consiste exatamente no fato de que diante do aumento da carga tributária há possibilidade de mudança de mentalidade dos produtores e consumidores, no sentido de readequarem seus processos e hábitos para uma utilização mais eficiente e equilibrada dos recursos naturais e dos produtos deles oriundos. Além disso, pode gerar receitas necessárias aos investimentos públicos em projetos de melhoria da qualidade ambiental.

Tais vantagens não superam algumas dificuldades operacionais e efeitos indesejáveis. É preciso considerar que a instituição de tributos que tenham por finalidade mudar o comportamento dos agentes econômicos deve ocorrer em produtos com demanda elástica a preço. Isso em razão dos resultados da tributação sob produtos com demanda inelástica a preço serem inócuos. Nesse caso, os poluidores repassariam os preços aos consumidores e continuariam poluindo. Logo, não se atingiria o objetivo maior, qual seja, mudança de comportamento dos agentes econômicos (SETTE; NOGUEIRA, 2007).

Outra desvantagem atribuída aos tributos ambientais consiste na complexidade dos cálculos dos custos envolvidos nas externalidades tributáveis e aos inúmeros obstáculos à obtenção de dados, que permitam a definição das respectivas bases de cálculo e alíquotas de acordo com o tipo de fonte emissora e com as características peculiares aos diversos seguimentos econômicos. Entre os efeitos indesejáveis também estão os impactos verificados nas classes sociais de menor renda, como corte de postos de trabalho e menor 
Direito tributário ambiental: benefícios fiscais às empresas para proteção...

acesso a bens de consumo. Há, ainda, os efeitos negativos sobre a competitividade, pois dependendo do grau e forma com que um país onera a atividade econômica por meio dos tributos ambientais pode, na verdade, estar aniquilando a competitividade da empresa no cenário das relações internacionais de comércio. Em um mundo globalizado e eminentemente competitivo, qualquer custo extra de produção consegue facilmente alterar o preço final do produto.

\subsection{Benefícios Fiscais}

Quando é colocada em pauta a discussão acerca da tributação ambiental, outra questão polêmica é se a proteção do meio ambiente deve ocorrer por meio da instituição de tributos ou por intermédio de benefícios fiscais. A fim de posicionar-se no debate, inicialmente, importa esclarecer a natureza desses benefícios e abordar algumas polêmicas que envolvem o tema.

Por intermédio dos benefícios fiscais o Poder Público procura alcançar três objetivos básicos:

1) estabelecer um modelo de desenvolvimento nacional, visando ao fortalecimento da economia;

2) estabelecer um modelo de desenvolvimento regional com os propósitos de integração nacional e recuperação econômica regional;

3) estabelecer uma política de desenvolvimento setorial, em face de algumas peculiaridades que justificam tratamentos especiais para alguns setores da economia (TRAMONTIN, 2002, p. 111).

Os benefícios podem ser de natureza não fiscal, como ocorre nos casos de doações de áreas a empresas para a exploração de atividades econômicas, ou de natureza fiscal, consistente em isenções, deduções e minoração dos elementos do critério quantitativo.

Adota-se a classificação de benefícios fiscais estruturada por José Nabais (1998, p. 670): benefícios fiscais estáticos ou benefícios fiscais stricto sensu e benefícios fiscais dinâmicos ou incentivos ou estímulos fiscais. Os primeiros contemplam a todos os contribuintes que se encontrem na situação visada. Dirigem-se a situações que já se verificaram, ou ainda que não se tenham verificado, não visam diretamente incentivar, mas apenas beneficiar por superiores razões de política geral econômica, social, cultural etc..

Os benefícios fiscais dinâmicos visam estimular ou incentivar determinadas atividades, estabelecendo uma relação entre as vantagens atribuídas e as atividades estimuladas. Enquanto nos benefícios estáticos a causa da concessão é a situação ou atividade em si mesma, nos benefícios dinâmicos a causa é a 
adoção futura do comportamento beneficiado ou o exercício futuro da atividade fomentada. Outrossim, os estímulos fiscais não são de atribuição generalizada, mas seletiva e dependem de específicos comportamentos contraprestacionais dos contribuintes. Nos benefícios fiscais, em sentido estrito, o direito a tratamento igual se impõe por via de regra, já nos benefícios fiscais dinâmicos, tal direito carece, em princípio, de qualquer suporte, até porque, para além do caráter seletivo que ostentam, a diferenciação de tratamento que ocasionam é compensada pelas contraprestações a que a sua concessão fica condicionada (NABAIS, 1998).

Os benefícios fiscais para fomento da proteção ao meio ambiente enquadram-se dentro da classificação dos benefícios fiscais dinâmicos, pois visam estimular atividades que modifiquem seu processo de produção ou produtos, a fim de eliminar ou ao menos minimizar os custos ambientais. São restritos às atividades que geram as externalidades negativas e sua concessão é condicionada à adoção do comportamento contraprestacional de proteção do meio ambiente. Como exemplo, cite-se a concessão de isenção de IPI a empresas que instalarem equipamentos antipoluentes. A concessão do benefício fiscal fica restrita as atividades que geram a externalidade ambiental que se visa eliminar ou minimizar e depende do agente econômico adotar o comportamento ambiental almejado.

A concessão de benefícios fiscais deve constituir meio adequado e necessário à consecução do respectivo objetivo econômico-social, bem como ser indispensável à intervenção do Estado. $\mathrm{O}$ seu critério deve ser a necessidade de beneficiação de um determinado setor de atividade econômico-social. Para tanto, após o decurso de um certo tempo de sua concessão, é preciso realizar controles dos seus resultados e efeitos. Devem ser mais adequados à realização dos objetivos que se propõem do que os outros meios alternativos à disposição do Poder Público (NABAIS, 1998).

É preciso uma seleção ajustada do círculo de pessoas a beneficiar, de modo que o âmbito pessoal de cada benefício fiscal seja escolhido e fixado em consonância com o objetivo que com ele se pretende atingir. Os inconvenientes gerais creditados apenas podem ser vencidos por benefícios fiscais que, por inequívocas razões do bem comum, sejam necessários e efetivamente adequados para a consecução do objetivo constitucionalmente estabelecido.

Tais renúncias somente são possíveis quando estiverem acompanhadas de estimativa do impacto-orçamentário financeiro, de modo que não afetem as metas dos resultados fiscais e estejam acompanhadas das medidas compensatórias no aludido período, conforme impõe o Art. 14 da Lei de Responsabilidade Fiscal (Lei Complementar 101/2000). 
Direito tributário ambiental: benefícios fiscais às empresas para proteção...

Acrescente-se a necessidade de o benefício fiscal ter duração delimitada, cláusula de reversão e um mínimo de contraprestação por parte do beneficiado (Art. 176 CTN). Isso porque, a desigualdade de tratamento entre empresas, a título de incentivos do Poder Público, somente encontra justificativa se houver razoabilidade na concessão e se buscar efetivamente a realização do interesse público previsto na Constituição.

\subsubsection{Vantagens dos Benefícios Fiscais}

Quando é colocada em pauta a discussão acerca da tributação ambiental, uma questão muito controvertida consiste em estabelecer qual o melhor meio para a implementação de políticas tributárias ambientais voltadas à alteração de condutas dos agentes econômicos em relação ao meio ambiente. As opções destacadas são: a instituição de tributos ou a concessão de benefícios fiscais. A opção pela concessão de benefícios fiscais é muito criticada. Entende-se que o Estado não deveria auxiliar os poluidores a suportar os custos do controle da poluição, pois estaria indo contra o princípio do poluidor-pagador, que carrega em si o ideal de que os maiores poluidores sejam os maiores contribuintes para a despoluição.

Já a instituição de ecotributos visa a internalização compulsória dos custos ambientais, impedindo que um determinado agente econômico poluidor imponha a toda a sociedade o ônus de suportar tal deseconomia. Ao não se atuar pela via tributária para internalização compulsória dos custos ambientais, possibilita-se que o produto seja colocado no mercado a um preço mais reduzido, subvencionado pelo conjunto da sociedade que suportará as externalidades negativas não consideradas. $O$ oposto ao princípio do poluidor-pagador é representado pelo princípio do ônus social, pelo qual os custos das medidas de implementação da qualidade ambiental recaem sobre toda a coletividade.

Mas o agente econômico somente irá lançar mão de mecanismos para proteção do meio ambiente, à medida que os custos para evitar o dano ambiental fiquem abaixo dos custos de reparação do dano. Acima desse limite perde-se o interesse por uma redução da poluição.

Nesse contexto, podem ser destacadas duas opções para a conservação do bem ambiental: ou deve o poluidor arcar com o emprego de instrumentos para diminuição da poluição, ou, por uma avaliação política, alivia-se o poluidor de tal encargo, devendo os prejudicados (sociedade) arcar com ele. Ocorre, então, uma subvenção do poluidor para que realize os investimentos necessários à eliminação ou redução da externalidade ambiental.

Cristiane Derani (2001) destaca que se a internalização dos custos ambientais 
fosse feita por meio da imposição de tributos, haveria necessariamente um aumento no preço da mercadoria, diminuindo a quantidade de sujeitos que têm acesso a ela. Por causa do aumento do custo, com a aquisição ou manejo dos recursos naturais, surge uma nova forma de exclusão da concorrência no mercado. $\mathrm{O}$ aumento do custo da produção leva à concentração de capital numa clara tendência monopolista. No desenvolvimento dessa prática não se atinge efetivamente o objetivo de conservação dos recursos naturais. $\mathrm{O}$ que ocorre é a transferência do uso da natureza para faixas cada vez mais seletas da sociedade. A qualidade de vida torna-se um bem de mercado acessível apenas a quem detém maior riqueza (DERANI, 2001).

Ainda que a tributação ambiental consista em um importante instrumento para a concretização do princípio do poluidor-pagador e custeio de atividades estatais com fins de promoção do ambiente, na atual realidade brasileira a carga tributária elevada (justificável diante do referencial constitucional de Estado que se buscou positivar) e os graves problemas sociais constituem óbices para a instituição de novos tributos com a finalidade de proteção do meio ambiente. Primeiramente, é preciso implementar na sociedade o hábito de consumo de produtos que não agridam o meio ambiente, por meio da informação e educação da população, demonstrando que práticas ambientais sustentáveis estão diretamente ligadas com a melhoria da qualidade de vida. Essas medidas também devem ser estendidas à iniciativa privada, para que a prática de ações ambientalmente responsáveis não constitua apenas uma questão de marketing, mas a verdadeira consciência de que a sua atividade acarreta problemas ambientais e sociais que precisam ser internalizados no processo de produção.

Da mesma forma, Consuelo Yoshida entende que em virtude desse processo de mudança de mentalidade, para observância espontânea das normas ambientais, ser lento, a efetividade da proteção do meio ambiente deve ser incrementada por meio de estratégias que aliem atrativos econômicos e financeiros às soluções técnicas adequadas. A autora pondera que:

O êxito e a efetividade da proteção ambiental dependem da adoção e implementação de políticas e ações que, a par das medidas de desestímulo à poluição e degradação ambientais, prestigiem, ao mesmo tempo, medidas de incentivo à prevenção, calcadas em atrativos econômico-financeiros (YOSHIDA, 2005, p. 533).

A Lei 6.938/81 prevê a possibilidade de concessão de benefícios fiscais, estabelecendo como instrumento da Política Nacional do Meio Ambiente: "os incentivos à produção e instalação de equipamentos e a criação ou absorção de 
Direito tributário ambiental: benefícios fiscais às empresas para proteção...

tecnologia, voltados para a melhoria da qualidade ambiental” (Art. $\left.9^{\circ}, \mathrm{V}\right)$. Esses incentivos podem ser de natureza tributária, conferindo-se, por exemplo, isenções.

Antonio Carrazza (2005, p. 660), destaca que "a lei tributária é melhor obedecida quando, em lugar de determinar condutas, vale-se do meio mais sutil de influenciá-las, outorgando aos contribuintes subvenções, isenções, créditos presumidos, etc". Esse artifício faz que as pessoas tenham a impressão de que são livres para conduzir seus negócios e, portanto, tendem a realizar a conduta socialmente desejada. Complementa que ao utilizar o mecanismo da extrafiscalidade para estimular comportamentos dos contribuintes, o Estado quase sempre obtém vantagens maiores do que se previamente arrecadasse os tributos para depois aplicá-los aos gastos públicos (CARRAZZA, 2005).

Pedro Herrera assevera que:

[...] deveria ser evitada a proliferação de novos impostos especiais em detrimento do sistema tributário. A verdadeira reforma tributária ecológica deve ocorrer introduzindo o interesse ecológico no sistema tributário e não convertendo o ordenamento tributário em uma selva de impostos indiretos ${ }^{1}$ (apud TÔRRES, 2005, p. 109).

Luis Eduardo Schoueri (2005) entende que a instituição de tributos ambientais apresenta o efeito indesejado de monetarização do Direito Ambiental. Utilizando-se o tributo com efeito indutor, o contribuinte não é mais visto como alguém que gera danos, mas como alguém que "paga a conta" e, portanto, está autorizado a consumir ou usar bens de natureza ambiental. A conseqüência, a médio prazo, é a redução de sua propensão a evitar práticas danosas ao ambiente, além da própria perda da consciência ambiental.

Alejandro Altamirano (2002) também reconhece que os benefícios fiscais são mais eficientes para o propósito de proteção ambiental. $\mathrm{O}$ agente poluidor avaliará a conveniência de optar por eles uma vez que, em geral, viabilizam a realização de seus objetivos comerciais. Uma política tributária que tenha por objetivo minimizar e prevenir os impactos ambientais da atividade econômica deve privilegiar os incentivos econômicos, ao invés de aumentar a carga tributária. Portanto, é melhor incentivar que penalizar, estimular a inversão nos controles da contaminação do que sancionar com gravames que podem asfixiar a atividade industrial (ALTAMIRANO, 2002, apud YOSHIDA, 2005, p. 538).

1 "debería evitarse una proliferación de nuevos impuestos especiales en detrimento del sistema fiscal. La verdadera reforma fiscal ecológica debe llevarse a cabo introduciendo el interés ecológico en el sistema fiscal y no convirtiendo el ordenamiento tributario en una selva de impuestos indirectos”. 
Ressalta-se que a concessão de benefícios fiscais deve ser restrita ao setor econômico gerador das externalidades que se visa eliminar. Consoante expõe Andrea Amatucci (2005) "a intervenção estatal deve restringir-se aos setores econômicos específicos, no intuito de reduzir aquele tipo e aquela quantidade de concentração de agentes poluentes, idôneos a por em crise o Estado de Bem-Estar Social garantido na Constituição ${ }^{2}$ (p. 61, tradução nossa). Nesse sentido que Lídia Ribas (2005) pondera:

A concessão de benefícios fiscais, como instrumento de política econômica-social, é legitimada constitucionalmente, mas não pode se dar de forma abusiva e servir ao favorecimento de interesses econômicos de grupos de pressão que exerçam influência ou pertençam às classes dirigentes, sob pena de comprometer a justiça fiscal. Seu manejo há de se dar de forma extraordinariamente prudente, considerando sua indispensabilidade [...] (p. 691).

\section{CONCLUSÃO}

Embora exista no ordenamento jurídico brasileiro uma excelente previsão acerca da proteção do meio ambiente, para que esse direito fundamental seja materializado é preciso que o Poder Púbico e a coletividade cumpram com os deveres fundamentais inerentes a esse direito. E para tanto, é necessário modificar a atual racionalidade reducionista e instrumental que dirige as atividades econômicas e os padrões de consumo. O homem precisa visualizarse dentro do conceito de meio ambiente. Da mesma forma, a economia não pode ser separada do meio ambiente, por isso que as decisões econômicas devem considerar seus impactos sobre a natureza.

O próprio consumidor, diante da maior facilidade de acesso à informação no mundo globalizado, está mais exigente em relação aos produtos que adquire. Uma parcela dos consumidores já exige atitudes éticas das empresas. Por essa razão, as empresas voltam-se a chamada responsabilidade social. Essa deve ser entendida como a integração voluntária das preocupações sociais e ambientais na gestão empresarial.

Muitas empresas ainda não visualizam a responsabilidade social como um valor inerente aos seus negócios. Utilizam-na apenas como uma estratégia de marketing no intuito de construir uma imagem pública positiva. Mas a responsabilidade social não deve ser reduzida a uma mera estratégia

\footnotetext{
2 "l'intervento statale deve inerire ai singoli settori economici, allo scopo di ridurre quel tipo e quella quantità di concentrazione di agenti inquinanti, idoneo a porre in crisi lo Stato di benessere sociale garantito dalla Costituzione.”
} 
Direito tributário ambiental: benefícios fiscais às empresas para proteção...

mercadológica. Mesmo se a curto prazo há perspectiva de ganhos, deve ser vista como um dever moral dos empresários e como uma estratégia de sustentação do negócio e da sociedade a longo prazo.

Em virtude da maior parte dos dirigentes das empresas e dos próprios consumidores não adotar ações ambientalmente responsáveis, o atual modelo de gerenciamento das atividades econômicas e mercado consumidor deve ser modificado. A fim de implementar essas mudanças de mentalidade e comportamento, é imprescindível que o Estado, com fulcro no Art. 174 da Constituição Federal, intervenha sobre a Ordem Econômica.

Para implementação das políticas ambientais, a atividade interventiva deve conciliar os instrumentos normativos com os instrumentos econômicos. Dentre os instrumentos econômicos à disposição do Estado na tarefa de proteção do meio ambiente, os institutos do Direito Tributário Ambiental destacam-se pela sua eficiência na alteração de condutas. Podem ser aplicados com a finalidade extrafiscal de regulação, disciplina e organização das atividades privadas, compelindo-as a uma atuação mais racional, por meio do adequado controle e gestão dos recursos naturais.

A proteção ambiental, por intermédio do Direito Tributário, pode ocorrer pela instituição e majoração de tributos ou pela concessão de benefícios fiscais. A opção pela tributação destaca-se pela sua capacidade de internalização compulsória dos custos sociais decorrentes da atividade econômica, concretizando o princípio do poluidor-pagador. Com o aumento da carga tributária, há possibilidade de mudança de mentalidade dos produtores e consumidores, no sentido de readequarem seus processos e hábitos para uma utilização mais eficiente e equilibrada dos recursos naturais e dos produtos deles oriundos.

Não obstante as vantagens apresentadas pela tributação ambiental, elas não superam algumas dificuldades e efeitos indesejáveis, como: a complexidade dos cálculos dos custos envolvidos nas externalidades tributáveis; a dificuldade de obtenção de dados que permitam a definição do critério quantitativo; os impactos verificados nas classes sociais de menor renda e os impactos na concorrência.

Outro impasse consiste no fato do agente econômico somente adotar tecnologias e processos ambientalmente menos impactantes à medida que os custos com a adoção desses mecanismos conservacionistas fiquem abaixo do custo de reparação dos danos. A isso se agrega a elevada carga tributária brasileira e os graves problemas econômicos e sociais, que fazem a solidariedade social necessária para efetivar uma política de meio ambiente consistente permanecer apenas no reino das boas intenções. A relação entre a pobreza e os problemas sociais não deve ser menosprezada. Problemas ecológicos e sociais estão fortemente interligados e se reforçam mutuamente. 
Por essas razões, destaca-se que a preservação ambiental não deve ocorrer por meio de uma tributação acentuada, e sim com estímulos, benefícios, já que o que se busca em longo prazo (e que efetivamente garantirá a preservação do meio ambiente) é uma consciência ambiental na produção e consumo. $\mathrm{O}$ êxito da proteção ao meio ambiente depende da implementação de políticas e medidas que, além de desestimular a poluição, prestigiem a prevenção por meio de incentivos econômico-financeiros.

Ainda que a experiência com benefícios fiscais no Brasil guarde algumas máculas, tendo em vista que algumas políticas de governo conferiram incentivos que não trouxeram melhorias à sociedade, se forem conferidos pelo meio adequado e necessário à consecução dos objetivos econômico-sociais, expostos no Art. 170 da Constituição Federal, serão legítimos. É preciso uma seleção ajustada do círculo de pessoas a beneficiar, de modo que o âmbito pessoal de cada benefício fiscal seja escolhido e fixado em consonância com o objetivo que com ele se pretende atingir. Deve haver estimativa do impactoorçamentário financeiro e medidas compensatórias. É igualmente importante que tais benefícios tenham duração delimitada e contemplem cláusula de reversão e contraprestação por parte do beneficiado.

\section{REFERÊNCIAS}

ANTUNES, Paulo de Bessa. Direito Ambiental. 8 ed. Rio de Janeiro: Lumem Júris, 2005.

AMATUCCI, Andrea. L'Inerenza dell' Interesse Pubblico alla Produzione: Strumenti Finanziari e Tutela Ambientale. In TÔRRES, Heleno Taveira (Org.). Direito Tributário Ambiental. São Paulo: Malheiros, 2005.

BONAVIDES, Paulo. Curso de Direito Constitucional. 13 ed. São Paulo: Malheiros, 2003.

CARrAZZA, Roque Antonio. Curso de Direito Constitucional Tributário. 21. ed. São Paulo: Malheiros, 2005.

CARNEIRO, Ricardo. Direito Ambiental: uma abordagem econômica. Rio de Janeiro: Forense, 2003.

CORREAA, Filipe Toscano de Brito Simões; MEDEIROS, João Ricardo Costa. Responsabilidade Social corporativa para quem? In: BROCANELLI, Noelma (Org.). Responsabilidade Social das Empresas: a contribuição das universidades. São Paulo: Peirópolis, Instituto Ethos, 2003. v. 2. 
Direito tributário ambiental: benefícios fiscais às empresas para proteção...

DERANI, Cristiane. Direito Ambiental Econômico. São Paulo: Max Limonad, 2001.

FABIÃO, Maurício França. O Negócio da Ética: um estudo sobre o terceiro setor empresarial. In: BROCANELLI, Noelma (Org.). Responsabilidade Social das Empresas: a contribuição das universidades. São Paulo: Peirópolis, Instituto Ethos, 2003. v. 2.

FIORILlO, Celso Antônio Pacheco. Curso de Direito Ambiental. 5 ed. São Paulo: Saraiva, 2004.

GUALTIERI, Aline et al. Responsabilidade Social das Empresas e Comunicação. In: BROCANELLI, Noelma (Org.). Responsabilidade Social das Empresas: a contribuição das universidades. São Paulo: Peirópolis, Instituto Ethos, 2003. v. 2.

HERRERA MOLINA, Pedro Manuel; CARBAJO VASCO, Domingo. Marco conceptual, constitucional y comunitario de la fiscalidad ecológica. In: TÔRRES, Heleno Taveira (Org.). Direito Tributário Ambiental. São Paulo: Malheiros, 2005.

JIMÉNEZ HERNÁNDEZ, Jorge. El Tributo como instrumento de protección ambiental. Granada: Editorial Comares, 1998.

KUNG, Hans. Uma ética global para a política e economia mundiais. Rio de Janeiro: Vozes, 1999.

MACHADO, Paulo Affonso Leme. Direito Ambiental Brasileiro. 13. ed. São Paulo: Malheiros, 2005.

MILARÉ, Edis. Direito do Ambiente. 3. ed. São Paulo: Ed. Revista dos Tribunais, 2004.

MODÉ, Fernando Magalhães. Tributação Ambiental: a função do tributo na proteção do meio ambiente. 1a ed. Curitiba: Juruá, 2004.

NABAIS, José Casalta. O Dever Fundamental de Pagar Impostos. Coimbra: Livraria Almedina, 1998.

NOVOA, Cesar Garcia. El principio de seguridad juridica em materia tributaria. Madrid: Marcial Pons, 2000.

RIBAS, Lídia Maria Lopes Rodrigues. Defesa Ambiental: utilização de Instrumentos Tributários. In TÔRRES, Heleno Taveira (Org.). Direito Tributário Ambiental. São Paulo: Malheiros, 2005. 
SCHOUERI, Luis Eduardo. Normas Tributárias Indutoras em Matéria Ambiental. In TÔRRES, Heleno Taveira (Org.). Direito Tributário Ambiental. São Paulo: Malheiros, 2005.

SELICATO, Pietro. Capacità contributiva e tassazione ambientale. In TÔRRES, Heleno Taveira (Org.). Direito Tributário Ambiental. São Paulo: Malheiros, 2005.

SETTE, Marli Teresinha Deon; NOGUEIRA, Jorge Madeira. Relevância da análise dos aspectos econômicos na instituição de um tributo ambiental. Revista de Direito Tributário, São Paulo, v. 96, p. 211-224, 2007.

TRAMONTIN, Odair. Incentivos públicos a empresas privadas e guerra fiscal. Curitiba: Juruá, 2002.

TÔRRES, Heleno Taveira. Da relação entre competências constitucionais tributárias e ambiental: os limites dos chamados "tributos ambientais". In: (Org.). Direito Tributário Ambiental. São Paulo: Malheiros, 2005.

YOSHIDA, Consuelo Yatsuda Moromizato. Ênfase na prevenção: a utilização econômica dos bens ambientais e suas implicações. In: TÔRRES, Heleno Taveira (Org.). Direito Tributário Ambiental. São Paulo: Malheiros, 2005. 